\title{
New insights into the mortality risk from nasopharyngeal cancer in the national cancer institute formaldehyde worker cohort study
}

\author{
Matthias Möhner ${ }^{1}$, Yimeng Liư ${ }^{2}$ and Gary M. Marsh²*
}

\begin{abstract}
Background: Indications were found that a diagnostic bias could have contributed to the National Cancer Institute's (NCl) suggestion of a persistent increased mortality risk for nasopharyngeal cancer (NPC).

Methods: NCl provided the cohort data updated through 2004. We computed local county rate-based standardized mortality ratios (SMRs) for NPC and all other entities of the pharynx for two time periods. Moreover, SMRs were calculated for pharyngeal cancer in relation to study site by cumulative exposure to formaldehyde (FA).

Results: Overall, our results corroborate the indications of a diagnostic bias by strong but contrary temporal trends for NPC and pharynx, not specified. Moreover, it was shown that mortality risks were increased in the Wallingford cohort for all pharyngeal cancer combined and for pharyngeal cancer excluding NPC. In contrast, no increased risks for these categories were found in the nine other study sites combined.
\end{abstract}

Conclusions: Our re-analysis provided little or no evidence to support NCl's suggestion of a persistent association between FA exposure and mortality from NPC.

Keywords: Formaldehyde, Nasopharyngeal cancer, Cohort mortality study, Occupational health, National Cancer Institute, Re-analyses

In October 2009, a working group of the International Agency for Research on Cancer (IARC) unanimously reaffirmed the classification of formaldehyde as Group 1, based on sufficient evidence in humans of nasopharyngeal cancer (NPC), although a group of different working group members concluded in March of the same year that exposure to formaldehyde is unlikely responsible for the increased risks of NPC in woodworkers reported in most case-control studies and in a pooled reanalysis of cohort studies $[1,2]$. The reason for this somewhat contradictory assessment - workers in the plywood industry are one of the occupational groups most exposed to formaldehyde [3] - is probably the National

\footnotetext{
* Correspondence: gmarsh@pitt.edu

${ }^{2}$ Center for Occupational Biostatistics and Epidemiology and Department of Biostatistics, 7120 Graduate School of Public Health, University of Pittsburgh, 130 DeSoto Street, Pittsburgh, PA 15261, USA

Full list of author information is available at the end of the article
}

Cancer Institute (NCI) formaldehyde worker cohort study, the extended follow-up until 2004 of which had just been completed, even if the first publication of these data was dedicated to lymphohematopoietic malignancies [4]. This NCI cohort is the largest cohort of formaldehyde-exposed industrial workers and thus of particular interest for the evaluation of carcinogenicity. However, the IARC's conclusion takes only into account the update of follow-up until 1994 [5], which later turned out to be incomplete by comparing the number of deaths with those detected by the next matching with the National Death Index [4]. An updated analysis of nasopharyngeal cancer was not published until 2013, after it became apparent that the former results [5] were biased by the incompleteness of the follow-up $[6,7]$.

(c) The Author(s). 2019 Open Access This article is distributed under the terms of the Creative Commons Attribution 4.0 International License (http://creativecommons.org/licenses/by/4.0/), which permits unrestricted use, distribution, and reproduction in any medium, provided you give appropriate credit to the original author(s) and the source, provide a link to the Creative Commons license, and indicate if changes were made. The Creative Commons Public Domain Dedication waiver (http://creativecommons.org/publicdomain/zero/1.0/) applies to the data made available in this article, unless otherwise stated. 
Table 1 Distribution of pharyngeal cancer cases in the NCl-cohort by sub-localization and period of follow-up

\begin{tabular}{|c|c|c|c|c|c|c|c|c|c|}
\hline \multirow[t]{2}{*}{ ICD8 } & \multicolumn{3}{|c|}{ 1934-1979 } & \multicolumn{3}{|c|}{ 1980-2004 } & \multicolumn{3}{|c|}{ 1934-2004 } \\
\hline & Obs & Exp & SMR $(95 \% \mathrm{Cl})$ & Obs & Exp & SMR $(95 \% \mathrm{Cl})$ & Obs & Exp & SMR $(95 \% \mathrm{Cl})$ \\
\hline 146 (Oropharynx) & 5 & 2.96 & $1.69(0.55-3.95)$ & 8 & 8.74 & $0.92(0.40-1.80)$ & 13 & 11.70 & $1.11(0.59-1.90)$ \\
\hline 147 (Nasopharynx) & 7 & 2.17 & $3.23(1.30-6.65)$ & 4 & 3.61 & $1.11(0.30-2.84)$ & 11 & 5.78 & $1.90(0.95-3.40)$ \\
\hline 148 (Hypopharynx) & 2 & 1.85 & $1.08(0.13-3.91)$ & 3 & 4.57 & $0.66(0.14-1.92)$ & 5 & 6.42 & $0.78(0.25-1.82)$ \\
\hline 149 (Pharynx, unspecified) & 1 & 4.37 & $0.23(0.01-1.28)$ & 20 & 13.19 & $1.52(0.93-2.34)$ & 21 & 17.56 & $1.20(0.74-1.83)$ \\
\hline 146-9 (Pharynx) & 15 & 11.34 & $1.32(0.74-2.18)$ & 35 & 30.12 & $1.16(0.81-1.62)$ & 50 & 41.46 & $1.21(0.90-1.59$ \\
\hline
\end{tabular}

\section{Re-analysis of the $\mathrm{NCl}$ formaldehyde cohort}

A recent re-analysis of the NCI formaldehyde cohort showed that the observed overall increased risk for NPC was driven by results for only one study site (Plant 1 : Wallingford), and the results for the other nine study sites (Plants 2-9) were unremarkable [8]. The striking concentration of NPC cases in the Wallingford site had already been noted in the first analysis of the NCI-cohort $[9,10]$, but was not taken into account by $\mathrm{NCI}$ investigators in subsequent analyses based on extended follow-ups. In addition, an independent historical cohort and nested case-control study of workers from the Wallingford site found that the large NPC risk was strongly associated with external employment in the ferrous and non-ferrous metal industries of the local area (in particular, silversmithing) that entailed possible exposures to several suspected risk factors for upper respiratory system cancer (e.g., sulfuric acid mists, mineral acid, metal dusts and heat) [11].

\section{Extended re-analysis of the $\mathrm{NCl}$ formaldehyde cohort}

Indications were also found in a second independent reanalysis that diagnostic bias could have contributed to the elevated risk estimators for NPC, and it was suggested to carry out an expanded analysis of the NCI formaldehyde cohort to explore these findings further [12]. The analysis is based on the updated 2004 NCI formaldehyde cohort study data from NCI, the same data base

Table 2 Distribution of pharyngeal cancer cases in the $\mathrm{NCl}$ cohort by sub-localization and study site (1934-2004)

\begin{tabular}{llllll}
\hline ICD8 & Study site & Obs & Exp & SMR & $95 \%$ Cl \\
\hline 147 (NPC) & Wallingford & 6 & 1.08 & 5.57 & $2.04-12.1$ \\
$146,148,149$ & Wallingford & 11 & 6.58 & 1.67 & $0.83-2.99$ \\
$146-149$ & Wallingford & 17 & 7.66 & 2.22 & $1.29-3.55$ \\
147 (NPC) & All other plants & 5 & 4.70 & 1.06 & $0.35-2.48$ \\
$146,148,149$ & All other plants & 28 & 29.09 & 0.96 & $0.64-1.39$ \\
$146-149$ & All other plants & 33 & 33.79 & 0.98 & $0.67-1.37$ \\
$147($ NPC) & Total & 11 & 5.78 & 1.90 & $0.95-3.40$ \\
$146,148,149$ & Total & 39 & 35.67 & 1.09 & $0.78-1.49$ \\
$146-149$ & Total & 50 & 41.46 & 1.21 & $0.90-1.59$ \\
\hline
\end{tabular}

as previously used by Marsh and colleagues [8]. Moreover, the external comparison of mortality from pharyngeal cancer is also based on local mortality rates as before, which helps to adjust for geographic, cultural and economic factors possibly related to pharyngeal cancer mortality over time [8]. The recoding of one case, mentioned by Lucas [13] was not taken into account, because it is based on an autopsy or hospital report and not on the death certificate. However, a change of the database from mortality data to cancer registry data would only be permissible if a corresponding record-linkage were made for all study subjects.

The current re-analysis was extended to all subcategories of pharyngeal cancer (International Classification of Diseases, 8th revision (ICD8): 146-149). In order to recognize changes over calendar time, the time period of the initial analysis (1934-1979) was compared with that of the two extension periods for the cohort's follow-up (1980-2004). Moreover, we compared results between the Wallingford site with those from all other study sites combined.

Table 1 shows that 21 of 50 (42\%) observed cases of deaths from pharyngeal cancer were coded as pharynx, unspecified (ICD8: 149). This is exactly in line with the corresponding expected number of cases, calculated based on local mortality rates (42.4\%). However, a large difference in the percentage of observed deaths coded as pharynx, unspecified, exists between the two time periods (one death out of 15 (6.7\%) versus 20 out of 35 (57.1\%), respectively), whereas, this is not observed in the corresponding expected number of deaths $(38.5 \%$ versus $43.8 \%$, respectively). A comparison of the SMRs for single entities with regard to their distribution over the two time periods reveals a significant decrease in SMR for NPC (ICD8: 147) from 3.23 to 1.11. The test for heterogeneity [14] yields $\chi^{2}=4.40(p<0.05)$. In contrast, for pharynx, unspecified (ICD8: 149), a strong increase of the SMR from 0.23 to 1.52 was observed $\left(x^{2}=\right.$ $3.54(p=0.06)$. These results give clear indications of a diagnostic bias or even death certificate coding errors.

Our analysis by NCI study site showed that mortality risks were increased in the Wallingford cohort for all pharyngeal cancer combined and for pharyngeal cancer excluding NPC (Table 2). In contrast, no increased risks 
Table 3 Distribution of pharyngeal cancer cases in the NCl-cohort by cumulative exposure to formaldehyde and period of follow-up

\begin{tabular}{|c|c|c|c|c|c|c|c|c|c|}
\hline \multirow{2}{*}{$\begin{array}{l}\text { Exposure } \\
\text { (ppm-yr) }\end{array}$} & \multicolumn{3}{|c|}{ 1934-1979 } & \multicolumn{3}{|c|}{ 1980-2004 } & \multicolumn{3}{|c|}{ 1934-2004 } \\
\hline & Obs & Exp & SMR $(95 \% \mathrm{Cl})$ & Obs & Exp & SMR $(95 \% \mathrm{Cl})$ & Obs & Exp & SMR $(95 \% \mathrm{Cl})$ \\
\hline 0 & 2 & 1.06 & $1.89(0.23-6.83)$ & 3 & 2.43 & $1.24(0.25-3.61)$ & 5 & 3.49 & $1.43(0.47-3.35)$ \\
\hline$(0,0.5]$ & 8 & 3.59 & $2.23(0.96-4.39)$ & 15 & 12.25 & $1.22(0.69-2.02)$ & 23 & 15.84 & $1.45(0.92-2.18)$ \\
\hline$(0.5,5.5]$ & 3 & 4.13 & $0.73(0.15-2.12)$ & 9 & 9.94 & $0.90(0.41-1.72)$ & 12 & 14.07 & $0.85(0.44-1.49)$ \\
\hline$>5.5$ & 2 & 2.56 & $0.78(0.09-2.82)$ & 8 & 5.50 & $1.46(0.63-2.87)$ & 10 & 8.06 & $1.24(0.59-2.28)$ \\
\hline Total & 15 & 11.34 & $1.32(0.74-2.18)$ & 35 & 30.12 & $1.16(0.81-1.62)$ & 50 & 41.46 & $1.21(0.90-1.59)$ \\
\hline
\end{tabular}

for these categories were found in the nine other study sites combined, clearly demonstrating the significant differences in pharyngeal cancer risk between the Wallingford site and all other study sites. The test for homogeneity [14] supports this observation $\left(x^{2}=8.37 ; p\right.$ $<0.01$ ) as did the statistically significant (plant group $x$ formaldehyde exposure) interaction term computed in the recent re-analysis by Marsh and colleagues [8].

The comparison of exposure categories with regard to cumulative exposure gives no indication of a possible exposure-risk relationship either for the original or for the extended follow-up period (Table 3). A further comparison by plant group shows that the mortality increase for pharyngeal cancer in the Wallingford cohort is virtually the same in all exposure categories with the exception of the non-exposed group (Table 4). These findings support the hypothesis that external occupational exposures in the Wallingford cohort may be causative for the observed excess in pharyngeal cancer mortality.

\section{Conclusions}

The analyses presented here provide no any evidence for a relationship between exposure to formaldehyde and pharyngeal cancer mortality in Plants 2-10. The likelihood of a diagnostic or death certificate coding bias with respect to pharyngeal cancer appears be high, especially in the Wallingford cohort. Furthermore, the new findings support the hypothesis that occupational exposures external to the Wallingford cohort may be responsible for the excess of pharyngeal cancer in the Wallingford cohort. Our findings are consistent with other recent study results and reviews [15-20] and they do not

Table 4 Distribution of pharyngeal cancer cases in the $\mathrm{NCl}$ cohort by cumulative exposure to formaldehyde and study site (1934-2004)

\begin{tabular}{|c|c|c|c|c|c|c|}
\hline \multirow{2}{*}{$\begin{array}{l}\text { Exposure } \\
\text { (ppm-yr) }\end{array}$} & \multicolumn{3}{|c|}{ Plant 1 (Wallingford) } & \multicolumn{3}{|c|}{ Plant 2-10 (all other plants) } \\
\hline & Obs & Exp & SMR $(95 \% \mathrm{Cl})$ & Obs & Exp & SMR $(95 \% \mathrm{Cl})$ \\
\hline & 0 & 0.77 & & 5 & 2.72 & 1.84 \\
\hline (0.1) & 6 & 2.21 & $2.71(1.00-5.90)$ & 17 & 13.63 & $1.25(0.73-2.00)$ \\
\hline$(0.5,5.5]$ & 6 & 2.85 & $2.10(0.77-4.57)$ & 6 & 11.21 & 0.54( \\
\hline 55 & 5 & 1.83 & $2.73(0.89-6.38)$ & 5 & 6.23 & $0.80(0.26-1.87)$ \\
\hline Total & 17 & 7.66 & $2.22(1.29-3.55)$ & 33 & 33.79 & $0.98(0.67-1.37)$ \\
\hline
\end{tabular}

support the NCI's and IARC's suggested causal association between formaldehyde and the risk of NPC.

\section{Acknowledgments}

We obtained the $\mathrm{NCl}$ cohort data via a Data Transfer Agreement between the University of Pittsburgh and the National Cancer Institute's (NCl) Technology Transfer Center. We extend special thanks to Dr. Laura Beane Freeman of NCl's Division of Cancer, Epidemiology and Genetics and Dr. Laura Henmueller of the NCI Technology Transfer Center. We also thank Charles Alcorn and Steve Sefcik for computer programming support.

\section{Funding}

GM's, YL's and MM's work was part of his usual activities without any sponsoring.

\section{Availability of data and materials}

The data that support the findings of this study are available from National Cancer Institute's Technology Transfer Center but restrictions apply to the availability of these data, which were used under license for the current study, and so are not publicly available. Data are however available from the authors upon reasonable request and with permission of National Cancer Institute's Technology Transfer Center.

\section{Authors' contributions}

MM wrote a first draft of the manuscript. GM was a co-investigator of the reanalyses of the $2004 \mathrm{NCl}$ cohort data and earlier served as co-investigator on re-analyses of the $1994 \mathrm{NCl}$ cohort data. He took lead roles in the finalization of the manuscript. YL was the primary biostatistician on the project and contributed to the writing and editing of the manuscript. All authors read and approved the final manuscript.

\section{Authors' information}

MM is Head of the unit Statistical methods in epidemiology and biometry at the Federal Institute for Occupational Safety and Health (BAuA), which is a German Federal Departmental Research Institute. As a federal authority it is directly responsible to the Federal Ministry of Labor and Social Affairs (BMAS). It conducts research and development in the field of safety and health at work, promotes the transfer of knowledge into practice, advises policymakers and performs sovereign functions (https://www.baua.de). As part of his work activities, MM act as advisor in several committees in Germany that discuss and provide policy advice on occupational health issues, including the Medical Expert Advisory Board Occupational Diseases, which counsels the BMAS on the scientific prerequisites with regard to new legal occupational diseases. Evaluation of the risk associated with occupational exposure to formaldehyde is a current issue in the latter committee.

YL was a PhD student in the Department of Biostatistics at the University of Pittsburgh, Graduate School of Public Health and has co-authored earlier $r$ of the $\mathrm{NCl}$ cohort directed by GM.

GM is Professor of Biostatistics and Director of the Center for Occupational Biostatistics and Epidemiology at the University of Pittsburgh, Graduate School of Public Health. Since the 1980s, he has been involved in epidemiological research on the potential carcinogenicity of formaldehyde, including re-analyses of earlier updates of the $\mathrm{NCl}$ formaldehyde cohort and serving as principal investigator of an independent cohort study of workers from one of the $\mathrm{NCl}$ study plants. 


\section{Ethics approval and consent to participate}

This research was deemed exempt from human subjects review by the University of Pittsburgh Institutional Review Board.

\section{Consent for publication}

Not applicable.

\section{Competing interests}

GM's and YL's work on the current analysis and manuscript was donated, but based on earlier work performed under a sponsored research contract between the University of Pittsburgh and the Research Foundation Health and Environmental Effects, a not-for-profit affiliate of the American Chemistry Council. Otherwise, GM and YL have no competing interests. The funding agency played no role in the design, writing, interpretation and conclusions. MM declares that he has no competing interests. The decision to submit this manuscript for publication is that of the authors.

\section{Publisher's Note}

Springer Nature remains neutral with regard to jurisdictional claims in published maps and institutional affiliations.

\section{Author details}

${ }^{1}$ Federal Institute for Occupational Safety and Health, Berlin, Germany. ${ }^{2}$ Center for Occupational Biostatistics and Epidemiology and Department of Biostatistics, 7120 Graduate School of Public Health, University of Pittsburgh, 130 DeSoto Street, Pittsburgh, PA 15261, USA.

Received: 6 September 2018 Accepted: 13 February 2019

Published online: 20 February 2019

\section{References}

1. Straif K, Benbrahim-Tallaa L, Baan R, Grosse Y, Secretan B, El Ghissassi F, Bouvard V, Guha N, Freeman C, Galichet L, et al. A review of human carcinogens--part C: metals, arsenic, dusts, and fibres. Lancet Oncol. 2009;10: 453-4.

2. Baan R, Grosse $Y$, Straif K, Secretan B, El Ghissassi F, Bouvard V, BenbrahimTallaa L, Guha N, Freeman C, Galichet L, et al. A review of human carcinogens--part F: chemical agents and related occupations. Lancet Oncol. 2009;10:1143-4.

3. NIOSH. Formaldehyde: evidence of carcinogenicity. In: NIOSH Current Intelligence Bulletin No 34: NIOSH; 1981. p. 14

4. Beane Freeman LE, Blair A, Lubin JH, Stewart PA, Hayes RB, Hoover RN, Hauptmann M. Mortality from lymphohematopoietic malignancies among workers in formaldehyde industries: the National Cancer Institute cohort. J Natl Cancer Inst. 2009;101:751-61.

5. Hauptmann M, Lubin JH, Stewart PA, Hayes RB, Blair A. Mortality from solid cancers among workers in formaldehyde industries. Am J Epidemiol. 2004; 159:1117-30.

6. Beane Freeman LE, Blair A, Lubin JH, Stewart PA, Hayes RB, Hoover RN Hauptmann M. Mortality from solid tumors among workers in formaldehyde industries: an update of the $\mathrm{NCl}$ cohort. Am J Ind Med. 2013; 56:1015-26.

7. Marsh GM, Youk AO, Morfeld P, Collins JJ, Symons JM. Incomplete follow-up in the National Cancer Institute's formaldehyde worker study and the impact on subsequent reanalyses and causal evaluations. Regul Toxicol Pharmacol. 2010;58:233-6.

8. Marsh GM, Morfeld P, Zimmerman SD, Liu Y, Balmert LC. An updated reanalysis of the mortality risk from nasopharyngeal cancer in the National Cancer Institute formaldehyde worker cohort study. J Occup Med Toxicol. 2016;11:8

9. Blair A, Stewart P, O'Berg M, Gaffey W, Walrath J, Ward J, Bales R, Kaplan S, Cubit D. Mortality among industrial workers exposed to formaldehyde. J Natl Cancer Inst. 1986;76:1071-84.

10. Blair A, Stewart PA, Hoover RN, Fraumeni JF Jr, Walrath J, O'Berg M, Gaffey W. Cancers of the nasopharynx and oropharynx and formaldehyde exposure. J Natl Cancer Inst. 1987:78:191-3.

11. Marsh GM, Youk AO, Buchanich JM, Erdal S, Esmen NA. Work in the metal industry and nasopharyngeal cancer mortality among formaldehydeexposed workers. Regul Toxicol Pharmacol. 2007;48:308-19.
12. Möhner $M$, Wendt $A$. A diagnostic bias might be a much simpler explanation for the apparently elevated risk for nasopharyngeal cancer with respect to formaldehyde. J Occup Med Toxicol. 2016;11:54.

13. Lucas LJ. Misclassification of nasopharyngeal cancer. J Natl Cancer Inst. 1994:86:1556-8.

14. Breslow NE, Day NE. Statistical methods in cancer research: volume 2 - the design and analysis of cohort studies. Lyon: IARC; 1987.

15. Coggon D, Ntani G, Harris EC, Palmer KT. Upper airway cancer, myeloid leukemia, and other cancers in a cohort of British chemical workers exposed to formaldehyde. Am J Epidemiol. 2014;179:1301-11.

16. Siew SS, Martinsen Jl, Kjaerheim K, Sparen P, Tryggvadottir L, Weiderpass E, Pukkala E. Occupational exposure to wood dust and risk of nasal and nasopharyngeal cancer: a case-control study among men in four nordic countries-with an emphasis on nasal adenocarcinoma. Int J Cancer. 2017; 141:2430-6.

17. Xie SH, Yu IT, Tse LA, Au JSK, Lau JSM. Occupational risk factors for nasopharyngeal carcinoma in Hong Kong Chinese: a case-referent study. Int Arch Occup Environ Health. 2017;90:443-9.

18. Bachand AM, Mundt KA, Mundt DJ, Montgomery RR. Epidemiological studies of formaldehyde exposure and risk of leukemia and nasopharyngeal cancer: a meta-analysis. Crit Rev Toxicol. 2010;40:85-100.

19. Bosetti C, McLaughlin JK, Tarone RE, Pira E, La Vecchia C. Formaldehyde and cancer risk: a quantitative review of cohort studies through 2006. Ann Oncol. 2008;19:29-43.

20. Kwon SC, Kim I, Song J, Park J. Does formaldehyde have a causal association with nasopharyngeal cancer and leukaemia? Ann Occup Environ Med. 2018; 30:5.

\section{Ready to submit your research? Choose BMC and benefit from:}

- fast, convenient online submission

- thorough peer review by experienced researchers in your field

- rapid publication on acceptance

- support for research data, including large and complex data types

- gold Open Access which fosters wider collaboration and increased citations

- maximum visibility for your research: over $100 \mathrm{M}$ website views per year

At BMC, research is always in progress.

Learn more biomedcentral.com/submissions 